\title{
Optimization of Siderophore Production by Bacillus Subtilis DR2 and its Effect on Growth of Coriandrum Sativum
}

\section{Sonali Kumari}

Patna University

Shilpi Kiran

Patna University

Sushma Kumari

Patna University

PANKAJ KUMAR ( $\square$ guptapankaj23@gmail.com )

Dolphin (PG) Institute of Bio Medical and Natural Science

Abha Singh

Patna University

\section{Research Article}

Keywords: Rhizosphere, Siderophore, Bacillus subtilis, Coriandrum sativum, 16S rRNA

Posted Date: June 3rd, 2021

DOl: https://doi.org/10.21203/rs.3.rs-567897/v1

License: (c) (i) This work is licensed under a Creative Commons Attribution 4.0 International License. Read Full License 


\section{Abstract}

Under scarce iron conditions, several bacteria, fungi and plants, secrete ferric iron-specific ligands, generically termed as siderophores that are able to bind with insoluble ferric ion thereby making them available to the host organisms. Siderophore producing bacteria was isolated from the rhizospheric soil of Eragrostis cynosuroides by CAS agar screening and CAS-shuttle assay method. Among five positive isolates, DR2 produced a relatively high level of siderophore (69.81 SU\%) and was identified as catecholate type. Further, it was identified as Bacillus subtilis DR2 (KP455653) based on 16S rRNA gene sequencing and phylogenetic analysis. Media optimization revealed that the strain $B$. subtilis DR2 showed maximum siderophore yield (80.60 SU\%) under optimized condition of $72 \mathrm{~h}$ incubation at $35^{\circ} \mathrm{C}$ in succinate media at $\mathrm{pH} 8$, supplemented with sucrose as carbon and $\mathrm{NaNO}_{3}$ as nitrogen sources. It was further tested as seed inoculants under pot culture conditions and was found to be very efficient in seed germination and growth promotion of Coriandrum sativum. Thus, the present study signifies that $B$. subtilis DR2 may be a promising candidate with potential of plant growth promotion to be used as biofertilizer for various crops.

\section{Introduction}

Rhizosphere is a dynamic environment, harbouring diverse array of microorganims. It is a rich repository of plant growth promoting rhizobacteria that enhances crop productivity and maintains soil health in a sustainable way ${ }^{1}$. Bacteria that stimulate plant growth either directly or indirectly, have been regarded as plant growth promoting rhizobacteria (PGPR). They promote plant growth via different mechanisms to make the respective elements available, like nitrogen fixation $\left(\mathrm{N}_{2}\right)$, siderophore production $(\mathrm{Fe})$, IAA production, phosphate solubilisation $\left(\mathrm{PO}_{4}\right)$, etc. All of them have their own vital roles in plant growth promotion.

Iron is a vital trace element for living organisms. But due to very low solubility of $\mathrm{Fe}^{3+}$ in the earth's crust, its availability is limited and it cannot be utilized by them. The element is predominantly present as oxide and hydroxide forms with their characteristic very low solubility. In response to this, microorganisms have evolved a strategy for acquiring iron through siderophore production ${ }^{2,3}$.

A siderophore is a low-molecular weight, iron chelating compound having high affinity for ferric iron, converting them into ferrous form, which is to be further utilized in the metabolic processes ${ }^{4}$.

Rhizospheric bacteria capable of producing siderophores increase the bioavailability of iron near the root to promote plant growth ${ }^{5}$. Based on the ligands used to chelate ferric iron, bacterial siderophores are categorized into four types: catecholate, hydroxamate, carboxylate and salicylate ${ }^{6}$. Various bacterial species of Bacillus, Aeromonas, Aerobacter, Enterobacter, Escherichia, Mycobacterium, Klebsiella, Vibrio, Salmonella and Yersinia are reported to produce siderophores. Bacillus spp. is known to be excellent siderophore producers and stimulate plant growth through enhanced phosphate nutrition, iron, potassium and nitrogen uptake. Inoculation of crop plant with different strains of PGPR increased not only the yield 
but also the quality of various medicinal plants as well as spice crops ${ }^{7,8}$. Several PGPR have been isolated all over the world with only few being commercialized including the species of Bacillus, Pseudomonas, Azobacter, Enterobacter, Azosprillum, Klebsiella, Serratia and Variovorax ${ }^{9,10}$. Among them, Bacillus spp. are reported to secrete metabolites that provide considerable tolerance property in any adverse condition and prevent from pathogen infection, hence they are better for several crops ${ }^{11-13}$. Various PGPR attributes of Bacillus species involved in increased productivity of rice, maize, wheat, cucumber, soybean, potato, apple, tomato and ornamental plants has been validated through green house as well as field trials ${ }^{14}$. In the present scenario, the natal approaches are generally used as an alternative to chemical fertilizers for enhancing crop productivity apart from including plant nutrient management systems. It is opined that a potent PGPR is one that must be able to colonize plant rhizosphere, promote growth with its multi-spectrum mode of action, good survivality, ecofriendly, and tolerant to temperature, ultraviolet (UV) radiation, oxidizing agents and various other unfavourable conditions $^{15}$.

Eragrostis cynosuroides known as kusha or dharbham grass is a medicinal plant and has extensive properties of acting as antimicrobial, antioxidant and anticancerous agents. This plant has also an ability to absorb ultraviolet radiation ${ }^{16}$. In the view of aforesaid benefits this grass has been chosen because its growth is independent of any exogenous supply of chemical fertilizer and it grows luxuriantly attaining huge biomass in short period of time.

Coriandrum sativum (Coriander), a member of family Apiaceae is an important herbal spice crop, generally grown in winter season of India. Its different parts are valued for its culinary and medicinal properties. The green herb being sink of various vitamins like, vitamin $A$, vitamin $C$, and vitamin $B_{2}{ }^{17,18}$ are used as flavouring agents in preparation of delicacies (sauces, soup, breads, cakes, confectionery and meat products), while the seeds act as tonic, stomachic, diuretic, carminative and aphrodisiac.

So keeping in mind, the immersing importance of coriander crop, the present study is aimed for production and estimation of siderophores produced by $B$. subtilis and their role in vegetative growth promotion of Coriandrum sativum seedlings under in vitro pot culture experiment.

\section{Materials And Methods}

\section{Iron Decontamination}

All glasswares used in the present study were soaked overnight in $6 \mathrm{M}$ hydrochloric acid $(\mathrm{HCl})$ and thoroughly rinsed with distilled water (DW) to remove any traces of iron.

\section{Sample collection and isolation of rhizospheric bacteria}

Rhizospheric soil sample of Eragrostis cynosuroides plant was collected from road side (devoid of any fertilizer) of Danapur, Patna, Bihar, India ( $25^{\circ} 34^{\prime} 56.2^{\prime \prime} \mathrm{N}, 85^{\circ} 2^{\prime} 37.06^{\prime \prime} \mathrm{E}$ ). The plant was uprooted with the help of trowel for the collection of rhizospheric soil. The soil sample was collected and transferred in 
sterile ziplock polythene bags to the laboratory for further study and processed within three hours. The soil suspension was prepared by adding $1 \mathrm{~g}$ of soil sample to $10 \mathrm{~mL}$ sterile DW and diluted up to $10^{-6}$ dilution and spread on to nutrient agar media (NAM) and incubated at $30 \pm 2{ }^{\circ} \mathrm{C}$ for $24 \mathrm{~h}$. Bacterial colonies appear on plates were purified; sub cultured repeatedly to get axenic culture and preserved at 4 ${ }^{\circ} \mathrm{C}$ in NAM for further use. The isolates were designated as DR1, DR2, DR3, DR4, DR5, DR6 and DR7. All the experiments were carried out in triplicates.

\section{Siderophore production}

\section{Preparation of Chrome Azurol S medium}

The Modified Chrome Azurol Sulfonate (CAS) agar plate ${ }^{19}$ was prepared by mixing two solutions given below:

Solution 1: It was prepared by dissolving $60.5 \mathrm{mg}$ CAS in $50 \mathrm{ml}$ de-ionized water and mixing it with a 10 $\mathrm{ml} \mathrm{Fe}{ }^{3+}$ solution (containing $1 \mathrm{mmol} \mathrm{L}^{-1} \mathrm{FeCl}_{3} \cdot 6 \mathrm{H}_{2} \mathrm{O}$ in $10 \mathrm{mmol} \mathrm{L}^{-1} \mathrm{HCl}$ ).

Solution 2: It was prepared by dissolving $72.9 \mathrm{mg}$ of hexa decyl trimethyl ammonium bromide (HDTMA) in $40 \mathrm{ml}$ de-ionized water resulting in a dark blue solution.

Both solutions (solution 1 and solution 2) were autoclaved separately and mixed slowly. The final mixture of $100 \mathrm{ml}$ volume was added to $900 \mathrm{ml}$ of succinate agar medium ( $\mathrm{pH}$ 7). After solidification of the media on petri plates, $24 \mathrm{~h}$ old bacterial isolates were inoculated and incubated at $30 \pm 2{ }^{\circ} \mathrm{C}$ for $24-72 \mathrm{~h}$. Formation of orange halo zone from dark blue color around the colonies was indicative positive result.

\section{Qualitative screening of siderophore production}

$24 \mathrm{~h}$ old bacterial isolates was spot inoculated on CAS agar plates (CAS dye + Succinate medium containing $\mathrm{K}_{2} \mathrm{HPO}_{4}(6 \mathrm{~g}), \mathrm{KH}_{2} \mathrm{PO}_{4}(3 \mathrm{~g}),\left(\mathrm{NH}_{4}\right)_{2} \mathrm{SO}_{4}(1 \mathrm{~g}), \mathrm{MgSO}_{4} .7 \mathrm{H}_{2} \mathrm{O}(0.2 \mathrm{~g})$, succinic acid $\left.(4 \mathrm{~g})\right)$ and incubated for 24-72 h. Change in color of the medium surrounding the test colony from blue to orange halo, indicated positive test for siderophore production.

\section{Quantitative Assay of siderophore production (CAS- Shuttle Assay)}

It was carried out by CAS shuttle assay ${ }^{19}$. The isolates were cultured in succinate medium and incubated in shaker incubator at $120 \mathrm{rpm}$ and $30 \pm 2{ }^{\circ} \mathrm{C}$ for $24 \mathrm{~h}$. The fermented broth was centrifuged at $10,000 \mathrm{rpm}$ for 10 minutes at $4{ }^{\circ} \mathrm{C}$. An aliquot of $0.5 \mathrm{ml}$ of supernatant (cell-free extract) was mixed with $0.5 \mathrm{ml}$ of CAS solution. The resulting color obtained was measured after $20 \mathrm{~min}$ of incubation at the wave length of $630 \mathrm{~nm}$, using the UV-VIS spectrophotometer (Systronics, Ahmedabad, India), referring the uninoculated CAS solution as blank. The percentage of siderophore units (SU) was estimated as the proportion of CAS color shifted using the formula:

$\%$ siderophore units $=[(\mathrm{Ar}-\mathrm{As}) / \mathrm{Ar}] \times 100$ 
Where,

$\mathrm{Ar}$ - absorbance of reference (CAS assay solution + uninoculated media) and

As - absorbance of the sample (CAS assay solution + cell-free supernatant).

\section{Phenotypic and genotypic characterization of isolates}

The most efficient isolate was further characterized on the basis of its morphological, cultural and biochemical characteristics as per the Bergey's Manual of Systematic Bacteriology. The potential strain was identified by $16 \mathrm{~S}$ rRNA gene sequence analysis. The sequence will be submitted to National Center for Biotechnology Information (NCBI) for accession number. PCR based 16S rRNA gene amplification and sequencing of the isolated bacterium was carried out using universal primers at Xcelris lab Ltd, Ahmedabad, Gujarat, India.

\section{Characterization of siderophores}

The characterization of the siderophore as catechol or hydroxamate types was carried out as follows:

Hydroxamate type of Siderophore (Tetrazolium salt test):

A pinch of tetrazolium salt and 1-2 drops of $2 \mathrm{~N} \mathrm{NaOH}$ was added to $0.1 \mathrm{ml}$ supernatant of the test culture. Instant appearance of a red to deep-red color was indicative of presence of hydroxamate siderophores $^{2}$.

Catecholate type of Siderophore (Arnow's Test):

In this assay $1 \mathrm{ml}$ of cell-free supernatant was mixed with $1 \mathrm{ml}$ of $0.5 \mathrm{M} \mathrm{HCl}$ and $1 \mathrm{ml}$ of nitrate molybdate to turn the mixture solution yellow. Further, $1 \mathrm{ml}$ of $1 \mathrm{M} \mathrm{NaOH}$ was added, mixed and incubated for $5 \mathrm{~min}$ at room temperature, resulting in red color formation. The color was stable for 1 hour and the absorbance was measured at $510 \mathrm{~nm}$ using a UV-VIS spectrophotometer ${ }^{20}$.

\section{Detection of siderophores by Thin Layer Chromatography (TLC)}

The culture supernatant of siderophore producer strain was spotted on $10 \times 20 \mathrm{~mm}$ silica gel plates and allowed to dry. The plates were run in an n-butanol: acetic acid: distilled water (12:3:5) solvent system until the solvent front reached the top. Thereafter it was dried and $0.1 \mathrm{M} \mathrm{FeCl}_{3}$ (prepared in $0.1 \mathrm{~N} \mathrm{HCl}$ ) was sprayed. Appearance of a wine-colored spot indicated a hydroxamate-type siderophore, while that of a dark gray spot indicated catechol-type siderophore ${ }^{21}$.

\section{Optimization of physicochemical parameters for siderophore production}

The biological production of siderophores is governed by several environmental factors like growth medium, temperature, $\mathrm{pH}$, incubation time, carbon sources, nitrogen sources etc. In the present study, the 
optimization experiments were initiated by evaluating the optimum nutrient medium for siderophore production. The three different nutrient media tested in the current study were Nutrient broth, JNFb' broth and Succinate broth. The siderophore production was monitored by using $50 \mathrm{ml}$ medium each, separately inoculated with $0.25 \mathrm{ml}$ of $24 \mathrm{~h}$ old culture, incubated at $37^{\circ} \mathrm{C}$ in shaker incubator (120 rpm for $24 \mathrm{~h}$ ).

The optimization of other physicochemical parameters for production of siderophores was studied by varying one parameter at a time, while keeping the others constant. These varying parameters included, incubation time $(24 \mathrm{~h}, 48 \mathrm{~h}, 72 \mathrm{~h}, 96 \mathrm{~h}, 120 \mathrm{~h})$, temperature $\left(25^{\circ} \mathrm{C}, 30^{\circ} \mathrm{C}, 35^{\circ} \mathrm{C}, 40^{\circ} \mathrm{C}\right)$, and $\mathrm{pH}(5,6,7,8,9$, 10). In addition, the effect of $0.1 \%$ solution of different carbon sources (glucose, sucrose, fructose, lactose, mannitol) and nitrogen sources (urea, sodium nitrate, ammonium sulphate) were also studied on siderophore production. The bacterial isolates were inoculated in the succinate medium and the estimation was done on the above mentioned quantitative assay.

\section{Pot experiment}

In order to evaluate the potential of selected isolate in coriander plant, a pot experiment was conducted in a growth chamber at the Department of Botany, Patna University. The coriander seeds purchased from local market (Bakarganj, Patna, Bihar, India) were surface sterilized by exposing to $2-3 \%$ of $\mathrm{NaOCl}$ followed by $70 \%$ ethanol solution for 3 min followed by rinsing with autoclaved DW, at least for three times ${ }^{10}$. Sterilized seeds were soaked in autoclaved DW for $24 \mathrm{~h}$ at room temperature inside closed petri dishes. Further seeds were transferred in bacterial suspension $\left(10^{8} \mathrm{cfu} \mathrm{ml}^{-1}\right)$ at $30^{\circ} \mathrm{C}$ for $6 \mathrm{~h}$ and sown in the pot having sterile soil (by autoclaving at $15 \mathrm{lbs} / 121^{\circ} \mathrm{C}$ for $3 \mathrm{~h}$ ) to a depth of $5 \mathrm{~mm}$ as a test (inoculated seeds) and control (uninoculated seeds) ${ }^{10}$. Sterile water was used for maintaining moisture in the pots as per requirements and observed for seed germination, root length and shoot length with respect to control and after two weeks, plants were harvested, roots were washed free of soil and shoot and root lengths were measured. The germination percentage was calculated. After one week, seedling vigour was recorded in terms of root and shoot length with the help of a measuring scale. Each treatment was carried out in three replications. Also number of normal and abnormal seedlings and dead seeds were counted. Germination percentage was determined by the following formula-

Germination $(\%)=$ Normal seedlings $/$ Total number of seed taken $\times 100$

The entire plant was dried in an oven at $72{ }^{\circ} \mathrm{C}$ for $48 \mathrm{~h}$ and fresh weight and dry weight were recorded as seedling growth parameter. Total biomass was calculated after deducting the dry weight from wet weight. The plants involved in our study comply with institutional guidelines.

\section{Statistical Analysis}

The data obtained were statistically analyzed by using software (SPSS 16.0), and graphically represented as the mean \pm standard deviation $(n=3)$.

\section{Results}




\section{Sample collection and isolation of mizospheric bacteria}

Choice for soil sample was guided by the luxuriant growth of Eragrostis cynosuroides on roadside, which are practically zero chemical fertilizer zones. Seven isolates (DR1-DR7) appeared on solid NAM, which upon repeated sub culturing retained their growth and preserved at $4{ }^{\circ} \mathrm{C}$ in NA medium.

\section{Qualitative screening of siderophore production}

Siderophore production is one of the important traits of PGPR. Since last few decades, they are attaining much attention because of their application in various other fields, apart from agriculture. In this context, the bacterial isolates were qualitatively screened for siderophore production trait. It was found that 5 out of 7 isolates gave positive test for the siderophore production with formation of varying intensity of orange zones (Fig.1) and were used for the further study. The zone of coloration was $13 \mathrm{~mm}, 31 \mathrm{~mm}, 16$ $\mathrm{mm}, 8 \mathrm{~mm}$ and $22 \mathrm{~mm}$ in DR1, DR2, DR4, DR6 and DR7 respectively.

\section{Quantitative assay for siderophore production}

The CAS forms a tight complex with the ferric ion resulting in blue coloration of medium, and upon addition of siderophores to the medium, iron are chelated from the dye complex, eventually changing the color of medium from blue to orange (Fig. 2). The zone sizes produced by these isolates and SU\% of siderophore production are represented in fig. 3. Among these 5 isolates, DR2 showed maximum siderophore production i.e. 69.81 SU\% in comparison to DR1 (27.51 SU\%), DR4 (31.95 SU\%), DR6 (15.67 SU\%) and DR7 (53.49 SU\%) and thus selected for further study.

\section{Phenotypic and genotypic characterization of isolates}

Morphological, physiological and biochemical characteristics of the potential isolate DR2 appeared as Gram positive, rod having motility and the colony with creamy white, round, irregular margin. The isolate was also foundd positive for oxidase, citrate, ammonia, Voges-Proskauer reaction and starch hydrolysis. Based on nucleotide homology and phylogenetic analysis of the 16S rRNA gene sequence showed the highest similarity with $B$. subtilis strain ZJHD1-70 (GenBank Accession Number: KF585036.1) (Fig. 4). So the isolate DR2 has been identified as $B$. subtilis. The nucleotide sequence analysis of the isolate DR2 was compared with available data base using BlastN tool on NCBI (http://www.ncbi.nlm.nih.gov/ BLAST). The nucleotide sequence of identified isolate was deposited as $B$. subtillis DR2 at NCBI with an accession number of KP455653 (Fig.4).

\section{Characterization of siderophores}

The selected strain B. subtilis showed a strong positive reaction with formation of red color in the Arnow's test and negative reaction in tetrazonium salt, infers the presence of catechol-type siderophore (Fig.5).

\section{Optimization of physicochemical parameters for siderophore production}


Optimization of nutrient media prior to physicochemical parameters is essential for ensuring maximum microbial growth and hence, maximum siderophore production. For this three different media viz., Nutrient broth, $\mathrm{JNFb}^{-}$and Succinate medium were individually inoculated with the test strain $B$. subtilis DR2. Among the three different nutrient media tested, highest siderophore production was observed in succinate medium (71.51 SU\%) followed by nutrient media (67.23 SU\%) and JNFb- (59.31 SU\%) (Fig. 6).

\section{Optimization of incubation time}

There is variation in siderophore production at various time intervals and was found to be optimum after $72 \mathrm{~h}$ incubation (72.48 SU\%). The isolate $B$. subtilis DR2 showed a gradual increase in siderophore production till $72 \mathrm{~h}$, after which the production declined from 50.38 to 32.36 at $96 \mathrm{~h}$ to $120 \mathrm{~h}$, respectively of incubation as noted in our study (Fig.7).

\section{Optimization of temperature}

The siderophore production varied with variation in temperatures and thus $35^{\circ} \mathrm{C}$ under shaking condition of $120 \mathrm{rpm}$ (74.54 SU\%) was observed for maximum production (Fig.8).

\section{Optimization of pH}

$\mathrm{pH}$ plays a vital role in the solubility of iron in production media and thereby, siderophore production. In our study the maximum siderophore production (75.80 \%) was found at pH 8.0 (Fig. 9).

\section{Optimization of carbon source}

It was carried out with different sources of carbon, such as sucrose, glucose, fructose, mannitol and lactose. Supplementation of growth media with various carbon sources increases the growth capacity of bacteria and therefore enhances siderophore production. In our investigation, presence of sucrose as Csource in the medium produced maximum (78.06 SU\%) siderophore as compared to other carbon sources (Fig.10).

\section{Optimization of nitrogen source}

During the evaluation of different suitable nitrogen sources in culture media, sodium nitrate was appeared to be the best suited for siderophore production as $80.60 \mathrm{SU} \%$ by $B$. subtilis DR2. The other nitrogen sources, such as ammonium sulphate (60.32 SU\%), potassium nitrate (43.86 SU\%) and urea (21.67 SU\%) gave lesser amount of siderophore production (Fig.11).

\section{Pot studies}

Pot culture complements to the field measurement in having experimental microbial status under controlled conditions. Application of this process favours, transferability of the experimental results to natural conditions. These experiments are cost efficient, easy to conduct and broadly applicable. Such pot culture is a simple and fast method to demonstrate that inoculation of rhizobacteria can increase the 
biomass and yield of any test plant. In our pot study, the results revealed that inoculation of Coriandrum sativum seeds with bacterial strain $B$. subtilis DR2 had a positive stimulatory effect on all the growth parameters, as compared to the control (Table 1). In the tested plant material \% enhancements in seed germination, root length, shoot length and biomass were recorded as $64,51.85,47.65$ and 70.94 , respectively (Fig.12).

\section{Discussion}

In the present study, 7 rhizospheric bacteria were isolated from the rhizosphere of grass Eragrostis cynosuroides (Kusha). Among them, 5 isolates (DR1, DR2, DR4, DR6 and DR7) were siderophore positive, of which the most promising isolate, namely DR2 (the highest Siderophore producing strain) was identified as $B$. subtilis DR2 based on its morphological, biochemical, and genotypic characters. Genus Bacillus is the most commonly reported PGPB with its well documented abilities of PGP properties like siderophore production, IAA production, nitrogen fixation, ACC deaminase synthesis and P-solubilization by numerous researchers ${ }^{22-24}$.

All the five siderophore producers showed more than $8 \mathrm{~mm}$ zone on CAS agar plate, where $B$. subtilis DR2 gave maximum siderophore zone of $31 \mathrm{~mm}$. There are similar reports of maximum siderophore zone by salinity tolerant $B$. subtilis $1(15.8 \mathrm{~mm})$, impacting on plant growth of wheat under saline soil ${ }^{25}$ and in Bacillus A6, DA11 and SS19 with $12.3 \mathrm{~mm}, 5.5 \mathrm{~mm}$ and $9.8 \mathrm{~mm}$, respectively, resembling our study ${ }^{26}$.

Upon quantitative assessment also, DR2 appeared as the best siderophore producer among all the isolates i.e., $69.81 \mathrm{SU} \%$, resembling with the reports on Bacillus sp. VITVK5 and Enterobacter sp. VITVK6 showing $60.06 \%$ and $61.79 \%$ siderophore production respectively 4 .

In another study, similar results were reported in B. subtilis CTS-G24 which produced $59 \%$ and $64 \%$ siderophore units in nutrient and succinate media, respectively ${ }^{27}$. On the basis of highest siderophore producing abilities, the DR2 was selected for further optimization and pot experiment studies.

Several workers across the globe reported several plant growth promoting rhizobacteria having ability to produce catecholates and hydroxamate type, siderophore ${ }^{28-30}$. In our investigation, $B$. subtilis DR2 showed a catechol-type siderophore, which is in accordance with the findings of other workers ${ }^{31}$. Another studies also confirmed the production of catecholate type of siderophore by Bacillus spp. under iron limiting condition ${ }^{32}$ and catecholic siderophore 2, 3-dihydroxybenzoate-glycine-threonine trimeric ester bacillibactin by $B$. subtilis strain $\mathrm{CAS} 5^{33}$. In the similar way, it has been stated that when the culture filtrates of the siderophore producers were analysed, there was revelation of presence of catechol type siderophores in $B$. subtilis and $R$. radiobacter, while hydroxamate-type siderophores for $P$. allii and $B$. megaterium ${ }^{29}$.

In the present work, the influence of $B$. subtilis physiology and the impact of various physical and chemical culture conditions on production of siderophore have been studied. Siderophores are iron- 
specific compounds, which are secreted under low iron stress conditions. B. subtilis DR2 showed maximum siderophore production in succinate medium, without the addition of iron, while its productivity may be repressed, due to presence of iron traces in nutrient broth and $\mathrm{JNFb}^{-}$broth media. Similar study has also been reported, in which succinate media supported maximum siderophore production (64 SU\%) by $B$. subtilis CTS-G24 ${ }^{27}$.

There are several reports on siderophore production by Bacillus spp., under the range of $24 \mathrm{~h}$ to $120 \mathrm{~h}$ of incubation $^{34,29}$. In the present investigation, $B$. subtilis DR2 achieved highest siderophore production (72.48 SU\%) at $72 \mathrm{~h}$ of incubation, which declined, thereafter. In accordance with this, optimum siderophore production at $72 \mathrm{~h}$ of incubation has been reported in Bacillus sp. IFM22 ${ }^{35}$. Other workers have reported highest production of siderophore ( $80 \mathrm{SU} \%$ ) by Bacillus sp. at an incubation period of 36 $h^{36}$.

Like incubation, microorganisms are also profoundly affected by temperature of their habitat, as it influences their growth and metabolite secretion. At low temperature, as the growth rate is slow, the siderophore production is also low. However, as the temperature increases up to optimal limit, the growth rate enhances, leading to production of more biomass, consequently higher amount of siderophore production takes place. In this study, $35^{\circ} \mathrm{C}$ was found to be optimum for siderophore production by $B$. subtilis DR2 (74.54 SU\%). Optimum production of siderophores have also been reported over a wide range of temperatures i.e., $25-45^{\circ} \mathrm{C}$ by Bacillus VITVK5, Bacillus VITVK6 and Enterobactersp..$^{37,38,4}$. However, similar to our findings, the temperature range of $37^{\circ} \mathrm{C}$ has been cited as optimum for siderophore production in $B$. anthracis ${ }^{39}$.

A change in $\mathrm{pH}$ of culture medium affects both microbial growth and bioavailability of iron ${ }^{40}$. In the present work, experiments investigating the effect of $\mathrm{pH}$, clearly reflected that the $\mathrm{pH}$, close to ambient condition (8.0) supported maximum growth and siderophore production. In Streptomyces fulvissimus also the highest siderophore production (93\% unit) was reflected at $\mathrm{pH} 8.0^{41}$. As per the report of Agro services international at a high $\mathrm{pH}$ value, insolubility of iron increases, which is in accordance with our finding ${ }^{4}$. During the optimization process, siderophore production showed an increase at $\mathrm{pH} 7.5$ and ranged between $18-30 \%$, while at $\mathrm{pH}$ of 8.5 , siderophore production was reported at peak, ranging from 30 to $60 \%$ by five bacteria (Bacillus cereus, Pseudoalteromonas tetraodonis, Micrococcus aloeverae, Psychrobacter pocilloporae, and Pseudomonas weihenstephanensis) ${ }^{31}$.

Carbon source provides energy for growth and various metabolic activities of microorganism. Siderophore production of $B$. subtilis is influenced by the nature of the carbon source. The present study on analysis of the effect of various carbon sources on siderophore production revealed that sucrose has most profound effect, acting as best inducer of $B$. subtilis DR2. Other workers have also reported sucrose, as best inducer of siderophore production in different species of Bacillus viz., Bacillus sp. VITVK5 as 83.17 SU\% ${ }^{4}$. Nitrogen, as one of the most important nutritional factors, serves as the building block material of organisms, so is used as the basal component of medium. Hence, various organic and 
inorganic compounds were tested in media as a source of nitrogen for siderophore production and sodium nitrate appeared to be the best suited for siderophore production as $80.60 \mathrm{SU} \%$ by B. subtilis DR2. Similar results were reported in the bacterial strains of Bacillus sp. VITVK5 (61.94\%) and Enterobacter sp. VITVK6 (61.32\%), where sodium nitrate was used as nitrogen source ${ }^{4}$.

In order to evaluate the PGP potential of $B$. subtilis DR2, its effect on seed germination of Coriandrum sativum has been investigated. The beneficial effects of the $B$. subtilis DR2 on the $C$. sativum were observed and evidenced by the increase in the \% germination, root length, plant fresh and dry biomass of the inoculated plants as compared to the non-inoculated controls (Table 1).

Our finding is similar to other reports, where the treatment of Coriandrum sativum plant with $B$. megaterium ISB28 produced highest shoot length $(16.07 \mathrm{~cm})$ being at par with Bacillus aerophilus Cor-15 $(15.20 \mathrm{~cm})$, B. subtilis NRCSS-I $(15.76 \mathrm{~cm})$ and $B$. subtilis NRCSS-II $(15.36 \mathrm{~cm})$ with respect to control $(12.20 \mathrm{~cm})$ and root length varied from $12.05,10.69,11.25$ and $11.13 \mathrm{~cm}$ with respect to control $8.64 \mathrm{~cm}$, respectively ${ }^{42}$. The enhancement in growth parameters after inoculation with $B$. subtilis DR2 may be, due to total nutrient uptake, different PGP activities, such as siderophore production, IAA production, phosphate solubilization, nitrogen fixation, etc ${ }^{43,23}$. These results corroborate with the previous finding, which reported that $B$. cereus ALT1 diminished Cd stress, strengthened antioxidant system and boosted growth in Soybean ${ }^{44}$. In a recent report, an endophytic bacteria $B$. subtilis has been observed to enhance drought tolerance and growth in wheat plant, due to its siderophore producing property ${ }^{45}$. Such sort of extensive research work becomes necessary as it reflects that replacement of chemical fertilizers with PGPR as inoculants is a much effective and sustainable approach for plant growth promotion.

\section{Conclusion}

Iron is a vital element required by all living organisms for their numerous cellular activities. Under irondeficit condition, microorganisms (PGPRs) produce low molecular weight siderophores to chelate iron $\left(\mathrm{Fe}^{3+}\right)$ molecules from the environment for their survival and support for overall crop improvement. The isolate $B$. subtillis DR2 was found to be quite effective in promoting seed germination and seedling growth of Coriandrum sativum, in terms of enhanced root, shoot length and biomass production. Therefore, it is suggested that the use of this potential strain as a potent biofertilizer can be beneficial for coriander cultivation and other crops also. Its application in pot experiment favours integration of biological management for plant improvement. The reproducibility of the result needs to be further standardized, so that the bacterium could be recommended as biofertilizers.

\section{Declarations}

\section{Availability of data and material}

The authors declare that all the data supporting the findings of this study are available within the article and from the corresponding authors on reasonable request. 


\section{Acknowledgement}

Authors are thankful to Department of Botany, Patna University, Patna, for providing the laboratory facilities to carry out the present investigation. The authors are also thankful to Xcelris, India for the molecular confirmation of our isolates by 16S rRNA gene sequencing.

\section{Contributions}

AS designed the research; SK (First author) conducted the experiment; SK $\left(1^{\text {st }}\right)$, SK $\left(2^{\text {nd }}\right.$ and $3^{\text {rd }}$ author), PK and AS analyzed data and wrote the paper. All authors have read and approved the final manuscript.

\section{Ethics declaration}

\section{Funding}

All authors declare that no any funding support has been received to carry out this work.

\section{Conflict of Interest}

All authors declare that there is no conflict of interest.

\section{Ethics approval}

The plants involved in our study comply with institutional guidelines.

\section{Consent for publication}

All authors agreed to publish this paper.

\section{References}

1. Kumar, A., Soni, R., Kanwar, S. S., \& Pabbi, S. Stenotrophomonas: A versatile diazotrophic bacteria from the rhizospheric soils of Western Himalayas and development of its liquid biofertilizer formulation. Vegetos. 32, 103-109 (2019).

2. Bholay, A. D., Jadhav, P. U., Borkhataria, B. V., \& Dhalkari, M. V. Fluorescent Pseudomona sas plant growth promoting rhizobacteria and their siderophore genesis. Pharm. Biol. Sci. 3(1), 27-32 (2012).

3. Kumar, P., Thakur, S., Dhingra, G. K., \& Singh, A. et al. Inoculation of siderophore producing rhizobacteria and their consortium for growth enhancement of wheat plant. Agric. Biotechnol.15, 264-269 (2018).

4. Kumar, V., Menon, S., Agarwal, H., \& Gopalakrishnan, D. Characterization and optimization of bacterium isolated from soil samples for the production of siderophores. Resource-Efficient Technologies. 3, 434-439 (2017). 
5. Alexander, D. B., \& Zuberer, D. A. Use of chrome azurol S reagents to evaluate siderophore production by rhizosphere bacteria. Biol Fertil soils. 12(1), 39-45 (1991).

6. Kannahi, M., \& Senbagam, N. Studies on siderophore production by microbial isolates obtained from rhizosphere soil and its antibacterial activity. Chem. Pharma. Res.6, 1142-1145 (2014).

7. Kumar, M., Prasanna, R., Bidyarani, N., Babu, S. et al. Evaluating the plant growth promoting ability of thermotolerant bacteria and cyanobacteria and their interactions with seed spice crops. Hortic.164, 94-101(2013).

8. Sahay, R., \& Patra, D. D. Identification and performance of sodicity tolerant phosphate solubilizing bacterial isolates on Ocimum basilicum in sodic soil. Eng.71, 639-643 (2014).

9. Glick, B. R. Plant growth-promoting bacteria: mechanisms and applications. Scientifica. (2012).

10. Kumar, P., Pahal, V., Gupta, A., Vadhan, R., Chandra, H., \& Dubey, R. C. Effect of silver nanoparticles and Bacillus cereus LPR2 on the growth of Zea mays. Rep.10, 1-10 (2020).

11. Radhakrishnan, R., Hashem, A., \& Abd_Allah, E. F. Bacillus: A biological tool for crop improvement through bio-molecular changes in adverse environments. Physiol.8, 667 (2017).

12. Hashem, A., Tabassum, B., Abd_Allah, E. F. Bacillus subtilis. A plant-growth promoting rhizobacterium that also impacts biotic stress. Saudi J. Biol. Sci.26, 1291-1297 (2019).

13. Kumar, P., Dubey, R. C., \& Maheshwari, D. K. Bacillus strains isolated from rhizosphere showed plant growth promoting and antagonistic activity against phytopathogens. Microbio Res. 167, 493-499 (2012).

14. Kashyap, B. K., Solanki, M. K., Pandey, A. K, Prabha, S., Kumar, P., \& Kumari, B. Bacillus as plant growth promoting rhizobacteria (PGPR): a promising green agriculture technology. In Plant health under biotic stress. Springer Singapore, pp 219-236 (2019).

15. Freschet, G. T., Roumet, C, Comas, L. H., Weemstra, M. et al. Root traits as drivers of plant and ecosystem functioning: Current understanding, pitfalls and future research needs. New doi.org/10.1111/nph.17072 (2020).

16. Barath, M., Aravind, J., \& Sivasamy, R. Investigation of Antimicrobial activity and Chemical Constituents of Eragrostis cynosuroides by GC-MS. J. Pharm. Technol.9(3), 267 (2016).

17. Girenko, M. M. Initial material and main directions of breeding of some uncommon species of vegetables. Biulleten-Vsesoiuznyi institut rastenievodstva. (1982).

18. Prakash, V. Leafy spices.CRC Press Inc Boca Raton, pp 31-32 (1990).

19. Schwyn B, Neilands, JB Universal chemical assay for the detection and determination of siderophores. Biochem.160, 47-56 (1987).

20. Arnow, L. E. Colorimetric determination of the components of 3, 4-dihydroxyphenylalanine-tyrosine mixtures. biol. Chem. 118(2), 531-537 (1937).

21. Colombowala, A., \& Aruna, K. Studies on optimization of siderophore production by Pseudomonas aeruginosa azar 11 isolated from aquatic soil and its antibacterial activity. J. Phar. Bio. Sci. 8, 714731 (2018). 
22. Zhang, L. N., Wang, D. C., Hu, Q., Dai, X. Q., Xie, Y. S., Li, Q., Liu, H. M., \& Guo, J. H. Consortium of plant growth-promoting rhizobacteria strains suppresses sweet pepper disease by altering the rhizosphere microbiota. Microbiol.10, 1668 (2019).

23. Yavarian, S., Jafari, P., Akbari, N., \& Feizabadi, M. M. Selective screening and characterization of plant growth promoting bacteria for growth enhancement of tomato, Lycopersicon esculentum. Iran J. Microbiol. 13, 121-129 (2021).

24. Zhou, L., Song, C., Li, Z., \& Kuipers, O. P. Antimicrobial activity screening of rhizosphere soil bacteria from tomato and genome-based analysis of their antimicrobial biosynthetic potential. BMC genomics.22, 1-14 (2021).

25. Jabborova, D. P., Narimanov, A. A., Enakiev, Y. I., Davranov, K. D. Effect of Bacillus subtilis 1 strain on the growth and development of wheat (Triticum aestivum) under saline condition. Bulg. J. Agric. Sci.26, 744-47 (2020).

26. Zulaika, E., Farisna, S. T., \& Laili, N. Bacillus as Siderophore and Iron-bioremoval Bacteria. Proceeding of 5th International Seminar on ISSN: 978-602-71169-7-9 New Paradigm and Innovation on Natural Sciences and Its Application (5th ISNPINSA) (2015).

27. Patil, S., Bheemaraddi, M. C., Shivannavar, C. T., \& Gaddad, S. M. Biocontrol activity of siderophore producing Bacillus subtilis CTS-G24 against wilt and dry root rot causing fungi in chickpea. IOSR Agric. Veteri. Sci. 7, 9 (2014).

28. Bhattacharyya, P. N., \& Jha, D. K. Plant growth-promoting rhizobacteria (PGPR): emergence in agriculture. World J. Microbiol. Biotechnol.28, 1327-1350 (2012).

29. Ferreira, C. M., Vilas-Boas, A., Sousa, C. A., Soares, H. M., \& Soares, E. V. Comparison of five bacterial strains producing siderophores with ability to chelate iron under alkaline conditions. AMB Express. 9, 1-12 (2019).

30. Ghazy, N., \& El-Nahrawy, S. Siderophore production by Bacillus subtilis MF497446 and Pseudomonas koreensis MG209738 and their efficacy in controlling Cephalosporium maydis in maize plant. Arch Microbiol. 1-15 (2020).

31. Sinha, A. K., Parli Venkateswaran, B., Tripathy, S. C., Sarkar, A., \& Prabhakaran, S. Effects of growth conditions on siderophore producing bacteria and siderophore production from Indian Ocean sector of Southern Ocean. Basic Microbiol.59, 412-424 (2019).

32. Bharucha, U. D., Patel, K. C., \& Trivedi, U. B. In vitro screening of isolates for its plant growth promoting activities from the rhizosphere of Alfalfa (Medicago sativa). Microbiol. Biotechnol. Res. 3, 79-88 (2013).

33. Wang, X. Q., Zhao, D. L., Shen, L. L., Jing, C. L., \& Zhang, C. S. Application and mechanisms of Bacillus subtilis in biological control of plant disease. In Role of rhizospheric microbes in soil. Springer Singapore, pp 225-250 (2018).

34. Gupta, A. \& Gopal, M. Siderophore production by plant growth promoting rhizobacteria. Indian J. Agric. Res.42, 153-6 (2008). 
35. Panda, S. H., Goli, J. K., Das, S., \& Mohanty, N. Production, optimization and probiotic characterization of potential lactic acid bacteria producing siderophores. AIMS Microbiol. 3, 88 (2017).

36. Patel, A. K., Ahire, J. J., Pawar, S. P., Chaudhari, B. L., Shouche, Y. S., \& Chincholkar, S. B. Evaluation of probiotic characteristics of siderophoregenic Bacillus isolated from dairy waste. Appl. Biochem. Biotechnol. 160, 140-155 (2010).

37. Christina, J. A., Sharmili, S. A., Anbumalarmathi, J., Umamaheswari, K., Shyamala, K. Studies on siderophore production by microbial isolates obtained from aquatic environment. J. Exp. Biol.5, 4145 (2015).

38. Chaudhary, D. Y., Osavi, P., \& Durve-Gupta, A. Isolation and application of siderophore producing bacteria. J. Appl. Res. 3, 246-250 (2017).

39. Wilson, M. K., Abergel, R. J., Arceneaux, J. E., Raymond, K. N., \& Byers, B. R. Temporal production of the two Bacillus anthracis siderophores, petrobactin and bacillibactin. Biometals. 23, 129 (2010).

40. Gaonkar, T., \& Bhosle, S. Effect of metals on a siderophore producing bacterial isolate and its implications on microbial assisted bioremediation of metal contaminated soils. Chemosphere. 93, 1835-1843 (2013).

41. Bendale, M. S., Chaudhari, B. L., \& Chincholkar, S. B. Influence of environmental factors on siderophore production by Streptomyces fulvissimus ATCC 27431. Trends Biotechnol. Pharm.3, 362371 (2010).

42. Mishra, B. K., Dubey, P. N., Aishwath, O. P., Kant, K. R., Sharma, Y. K., \& Vishal, M. K. Effect of plant growth promoting rhizobacteria on coriander (Coriandrum sativum) growth and yield under semi-arid condition of India. Indian J. Agric. Sci.87, 607-612 (2017).

43. Gouda, S., Kerry, R. G., Das, G., Paramithiotis, S., Shin, H. S., \& Patra, J. K. Revitalization of plant growth promoting rhizobacteria for sustainable development in Microbio. Res. 206, 131-140 (2018).

44. Sahile, A. A., Khan, M. A., Hamayun, M., Imran, M., Kang, S. M., \& Lee, I. J. Novel Bacillus cereus Strain, ALT1, Enhance Growth and Strengthens the Antioxidant System of Soybean under Cadmium Stress. Agronomy. 11, 404 (2021).

45. Lastochkina, O., Garshina, D., \& Pusenkova, L. Effect of endophytic Bacillus subtilis on drought stress tolerance of Triticum aestivum plants of Steppe Volga and Forest-Steppe West Siberian agroecological groups. 2nd International Conference Plants and Microbes: the Future of Biotechnology, Saratov, 5-9 (2020).

\section{Tables}

Table 1 Effect of Bacillus subtilis DR2 on seed germination and growth of Coriandrum sativum plant. 


\begin{tabular}{|llllllllll|}
\hline Plant & Treatments & $\begin{array}{l}\text { Germination } \\
\%\end{array}$ & \multicolumn{2}{l}{ Length(cm) } & \multicolumn{2}{l}{$\begin{array}{l}\text { Fresh } \\
\text { weight(g) }\end{array}$} & Dry weight(g) \\
& & & Shoot & root & shoot & Root & Shoot & Root \\
$\begin{array}{l}\text { Coriandrum } \\
\text { sativum }\end{array}$ & B.subtilis & 64 & 18.9 & 8.2 & 2.82 & 0.55 & 0.56 & 0.28 \\
\hline & Control & 52 & 12.8 & 5.4 & 1.52 & 0.36 & 0.23 & 0.17 \\
\hline
\end{tabular}

Figures

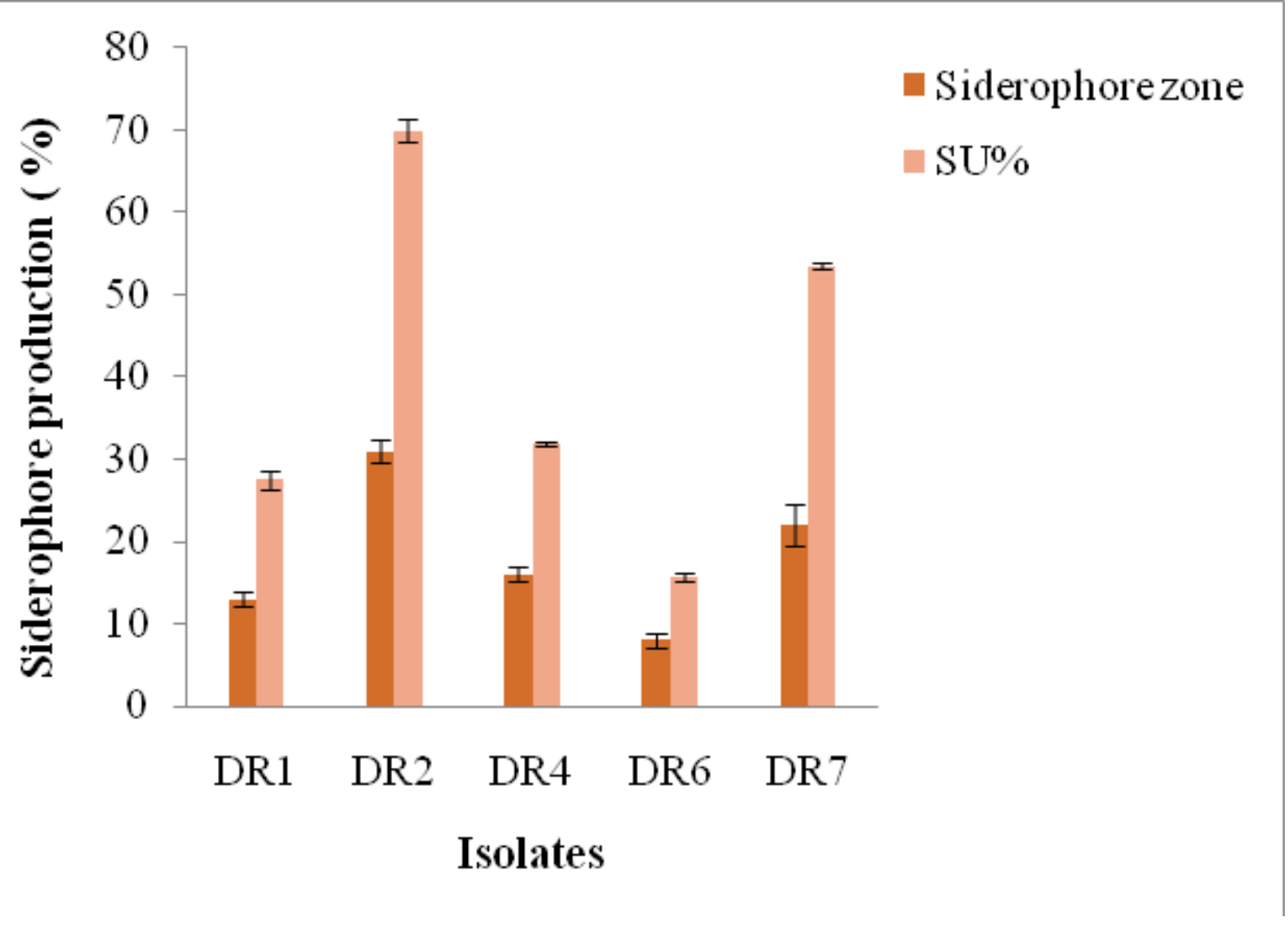

Figure 1

Qualitative and quantitative assessment of siderophore production by potential isolates 


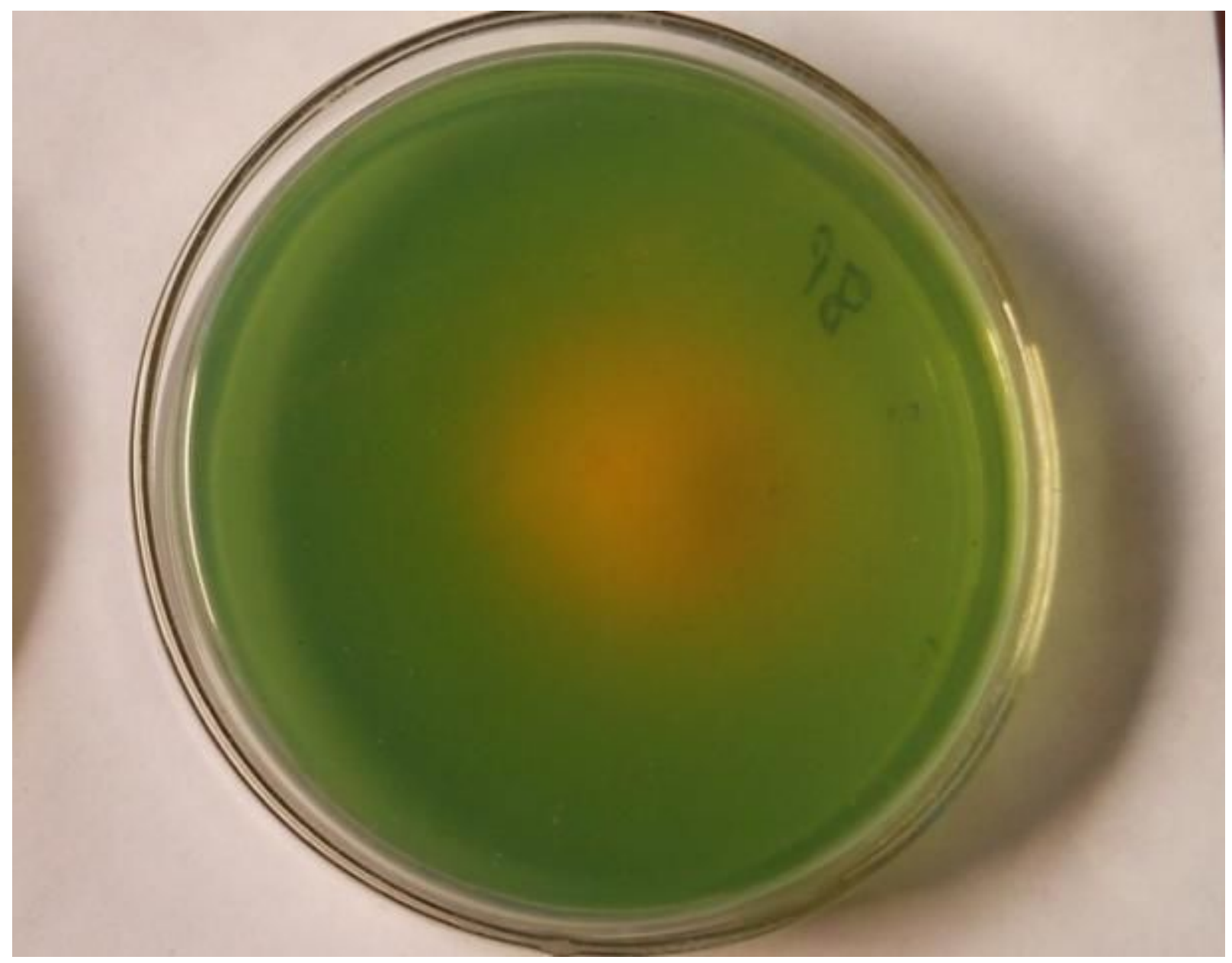

\section{Figure 2}

The appearance of orange color and zone formation by DR2 indicating siderophore production on CAS agar plate

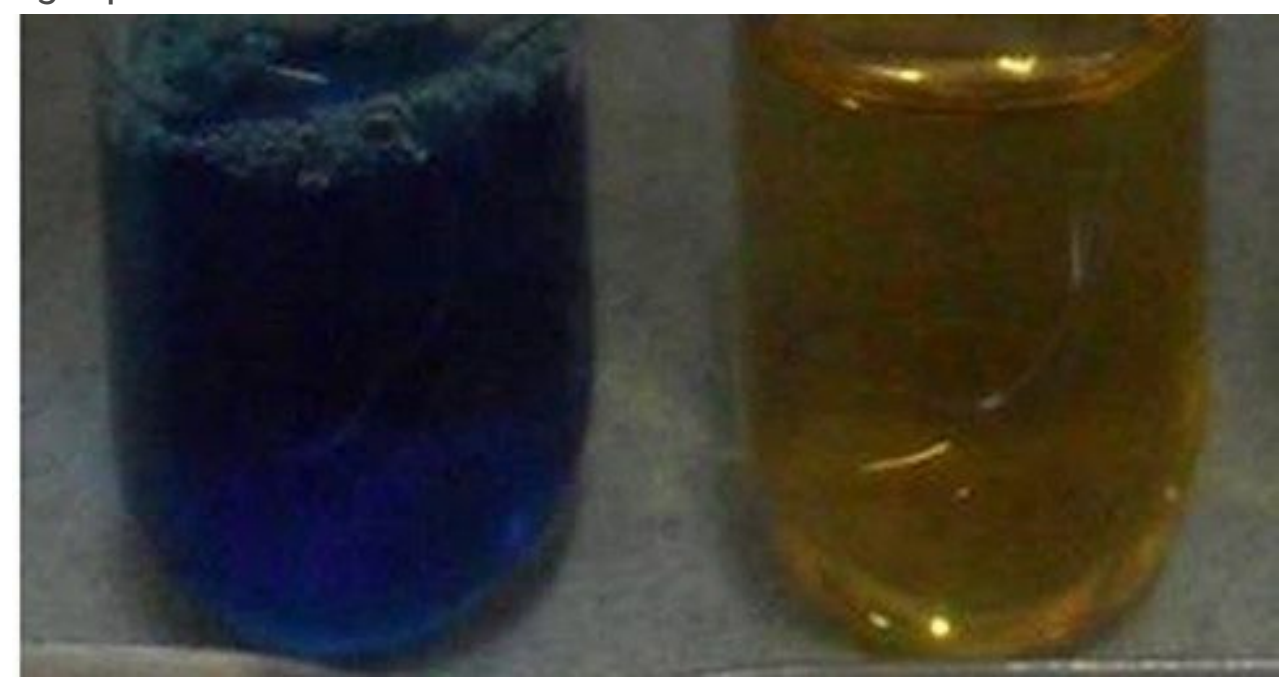

\section{Figure 3}

Quantitative estimation of siderophore production by DR2. 


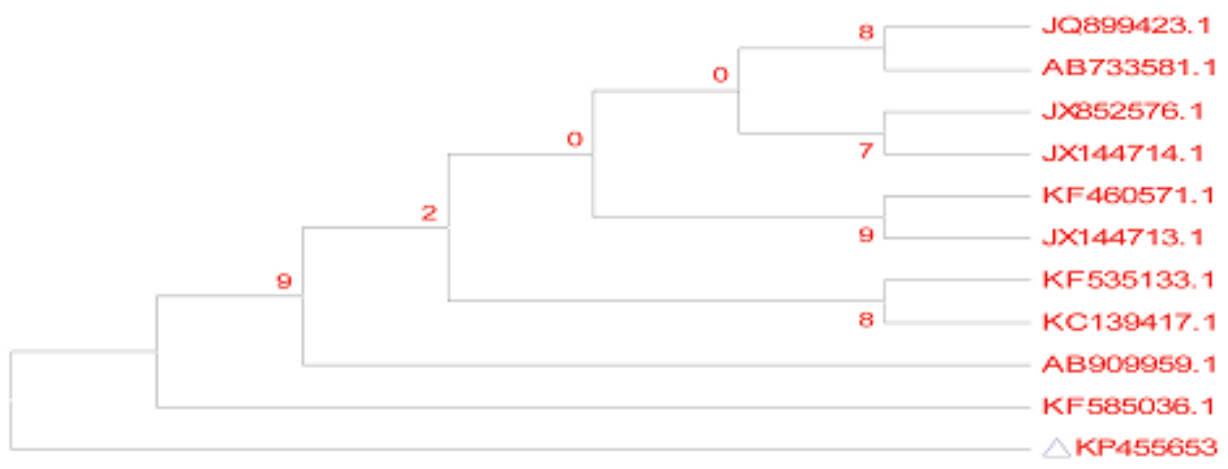

Figure 4

Phylogenetic tree showing genetic relationship with B. subtilis DR2 (Accession number KP455653)

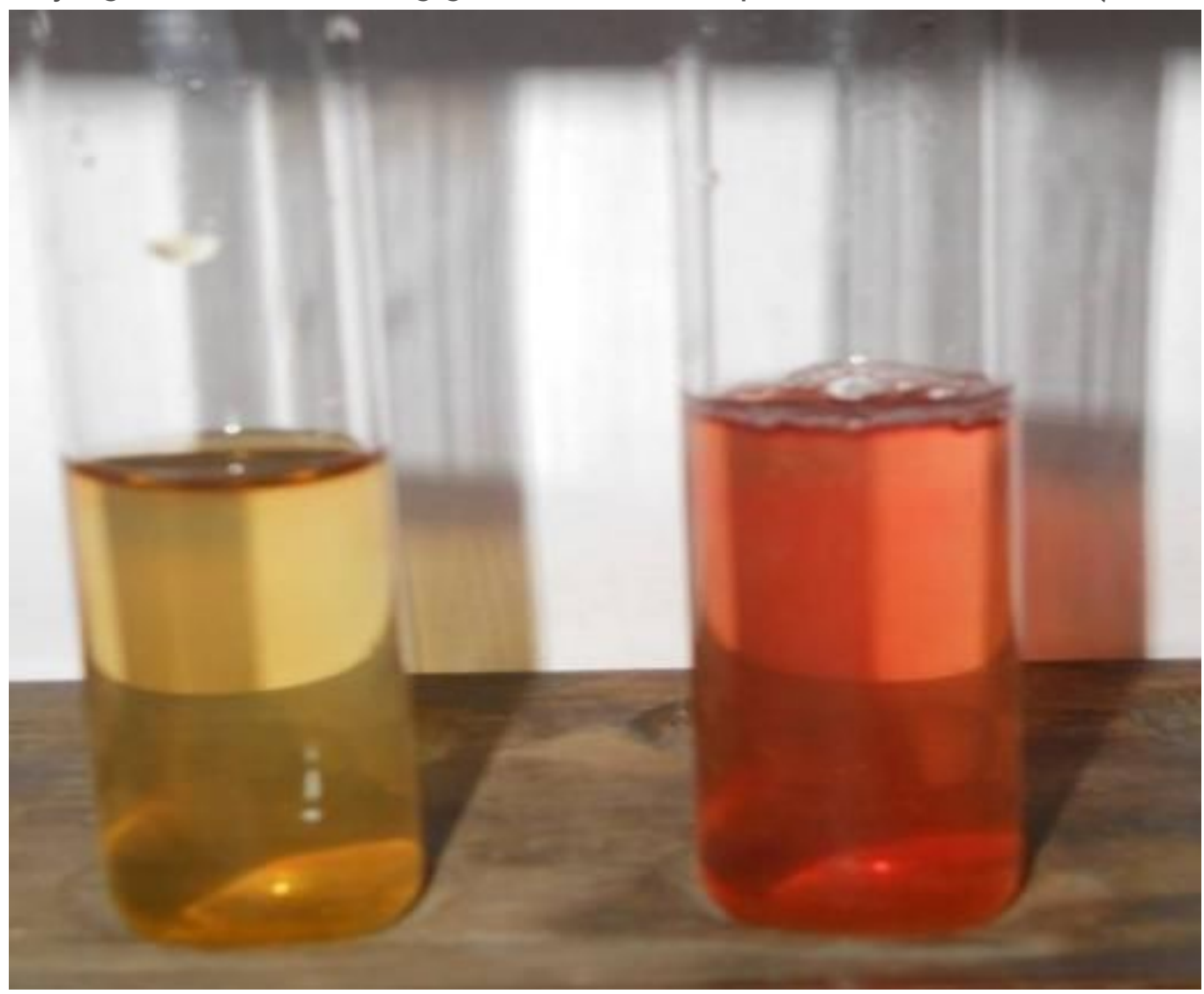

\section{Figure 5}

Instant appearance of red colour in Arnow's test 


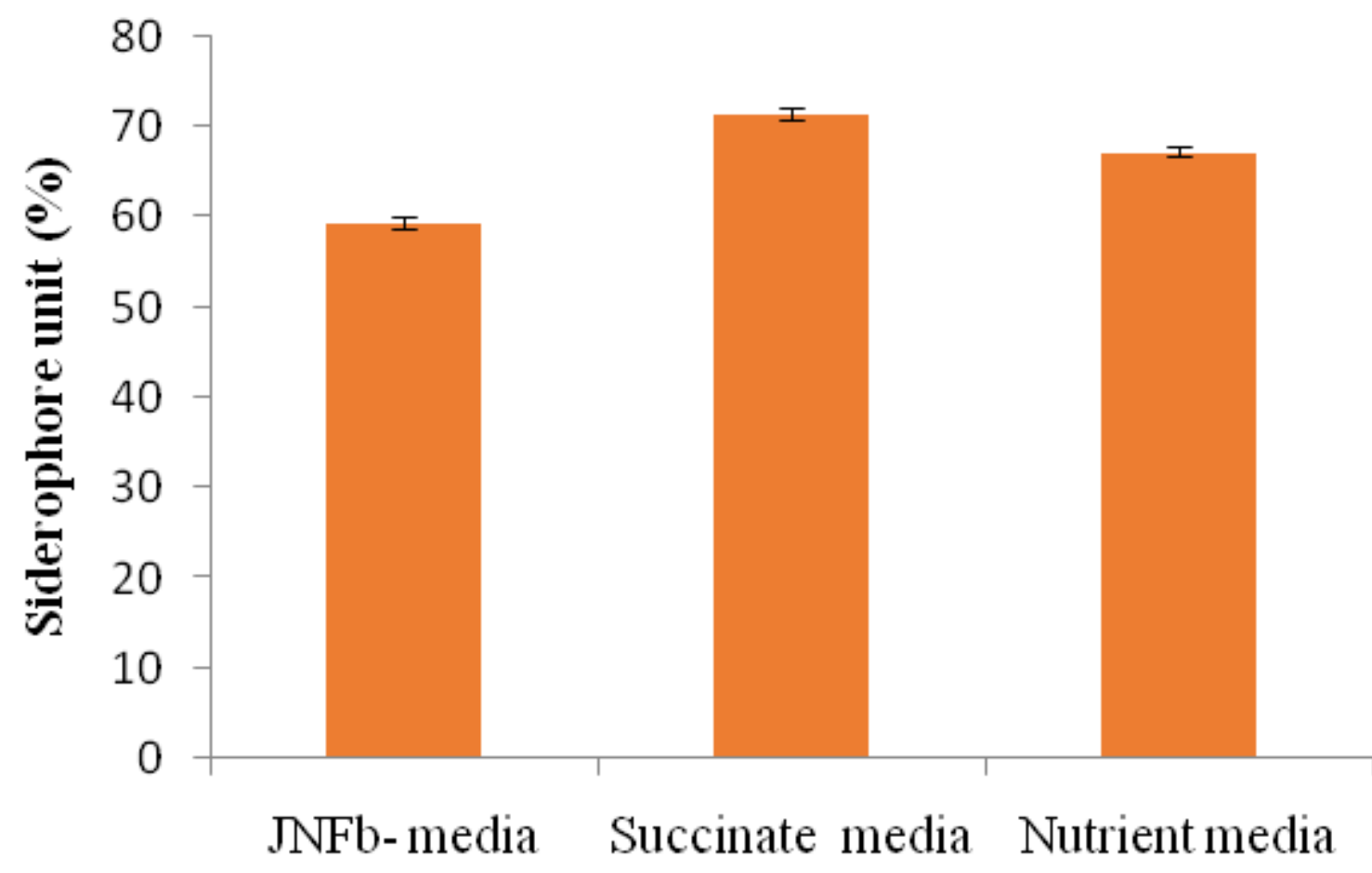

Figure 6

Effect of culture media on siderophore production by B. subtilis DR2 


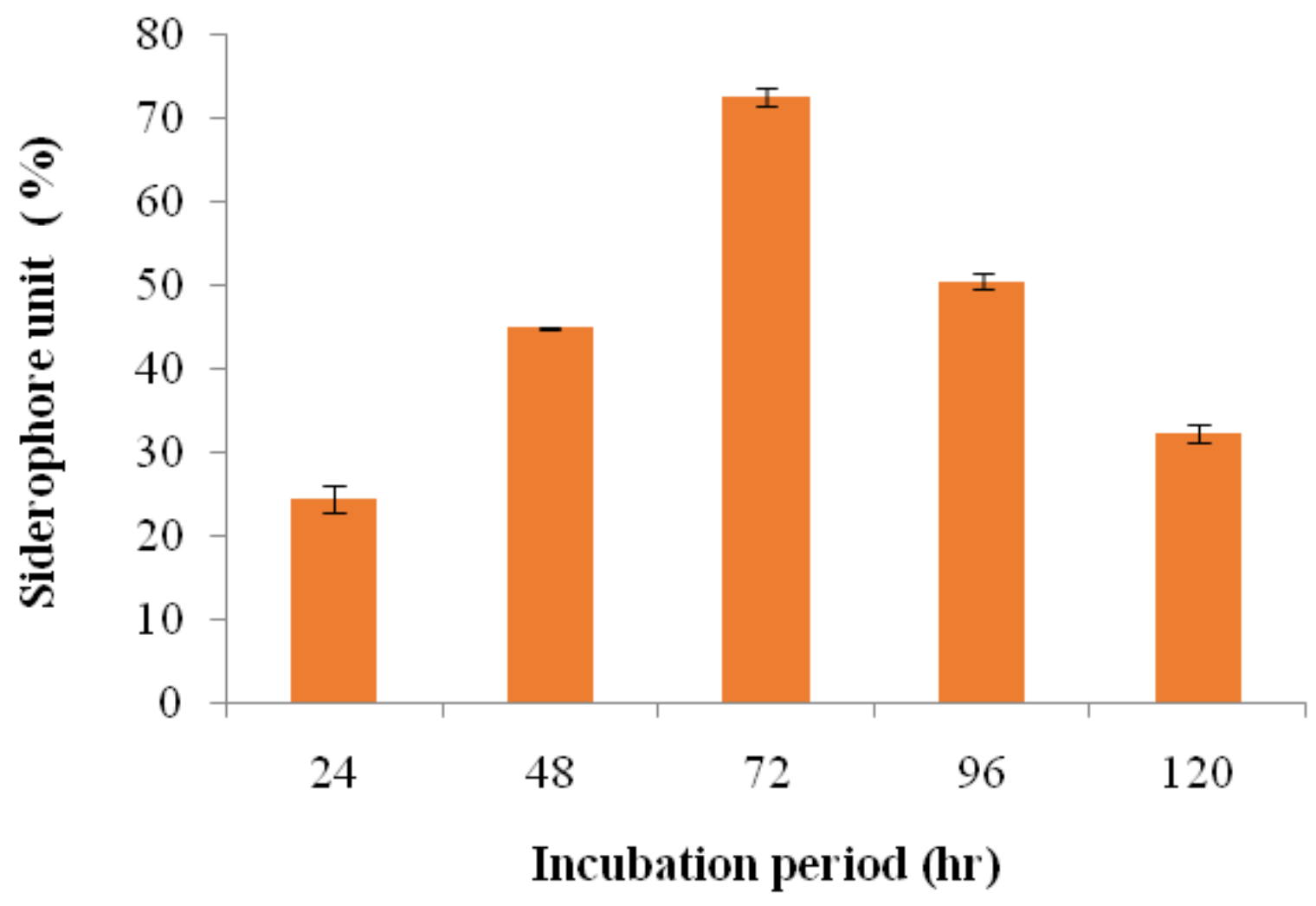

Figure 7

Effect of incubation time on siderophore production by B. subtilis DR2 


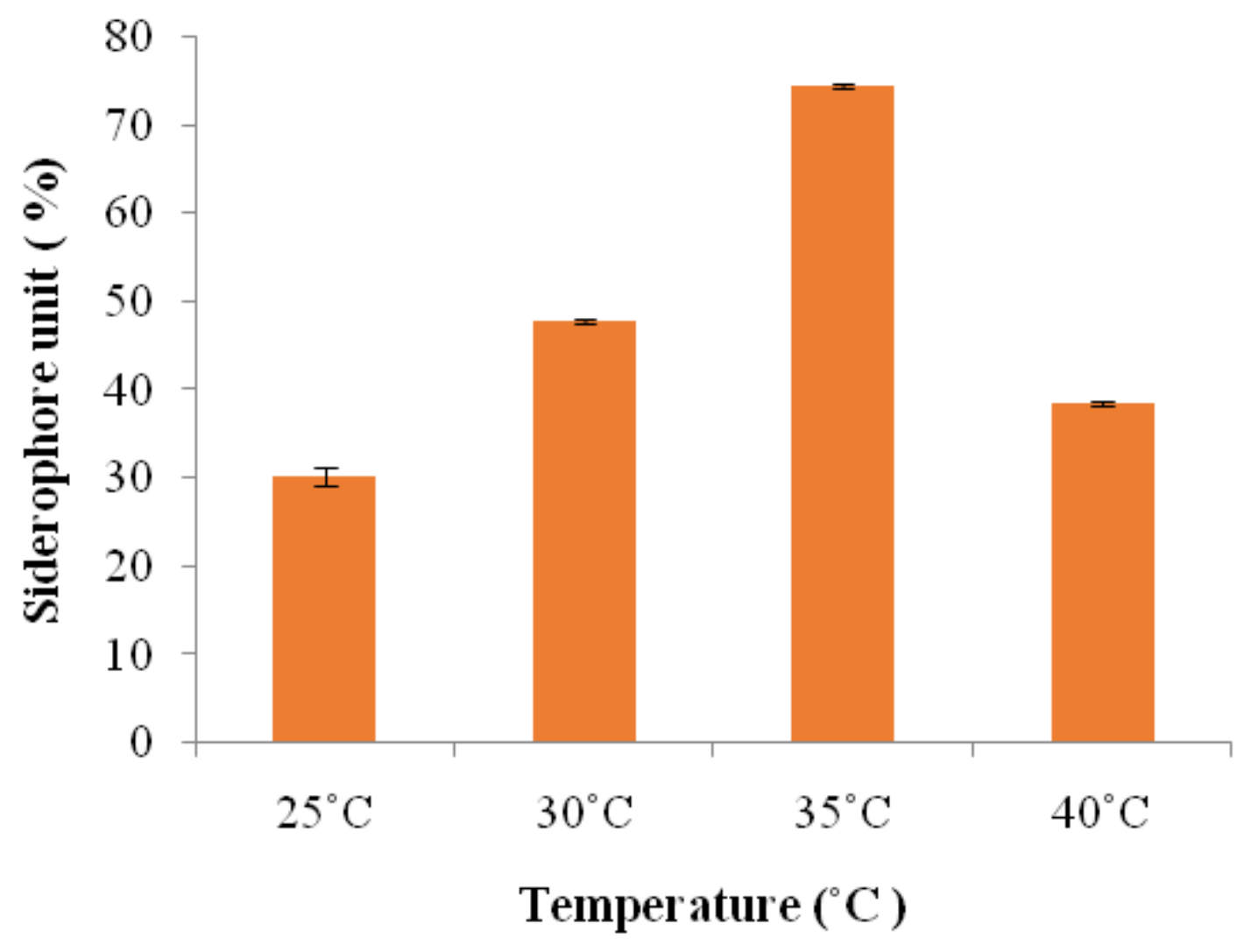

Figure 8

Effect of temperature on siderophore production by B. subtilis DR2 


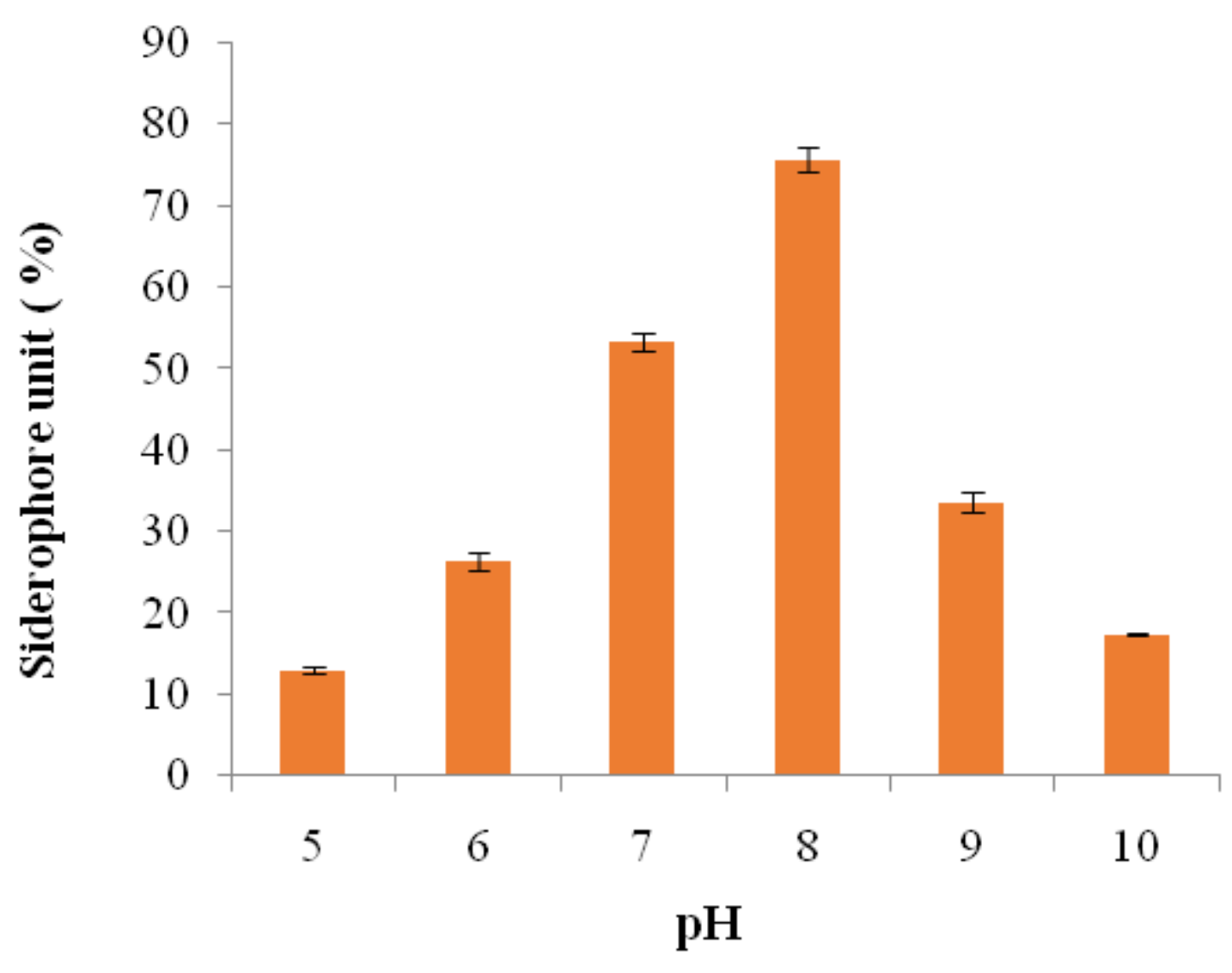

Figure 9

Effect of $\mathrm{pH}$ on siderophore production by B. subtilis DR2 


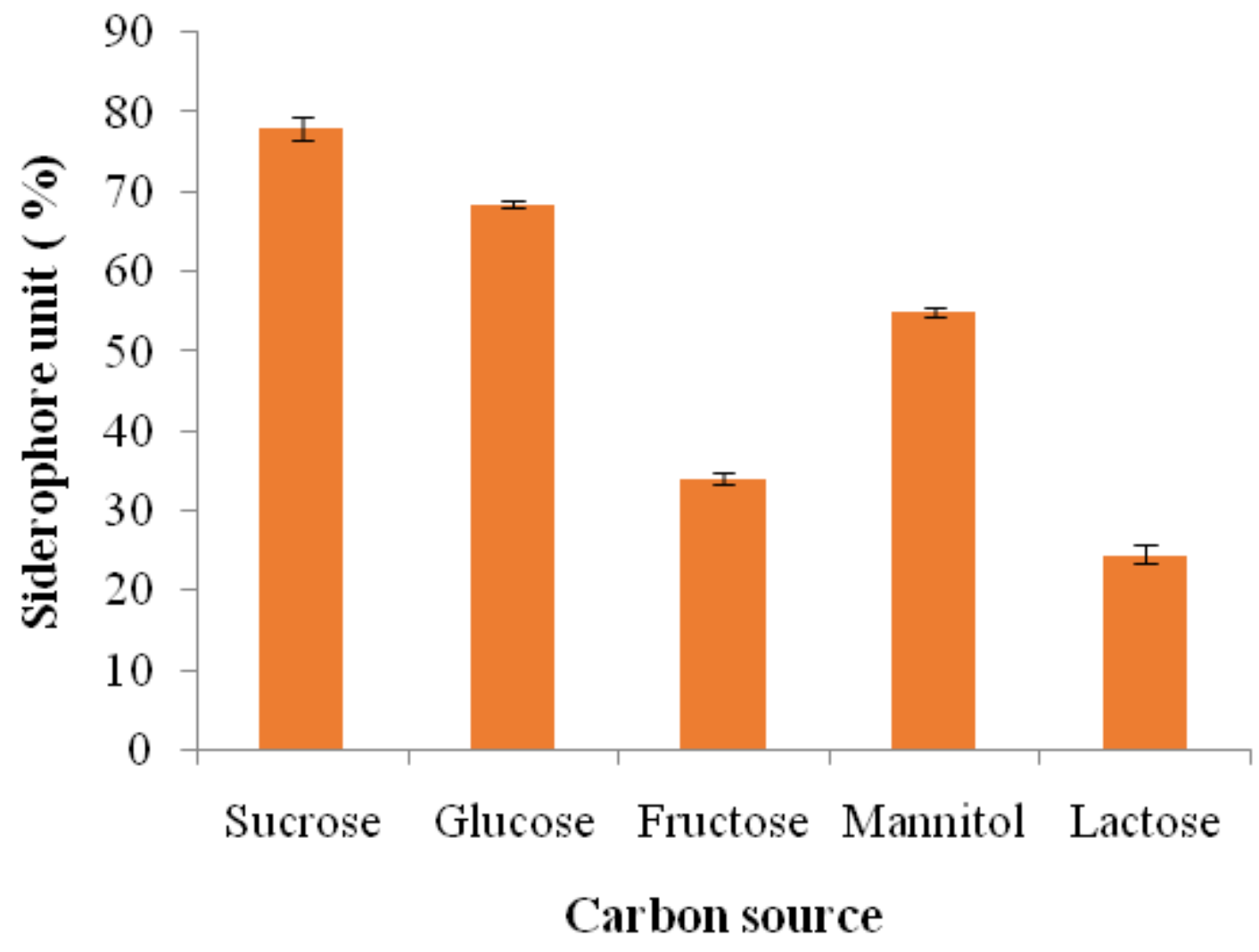

Figure 10

Effect of carbon sources on siderophore production by B. subtilis DR2 


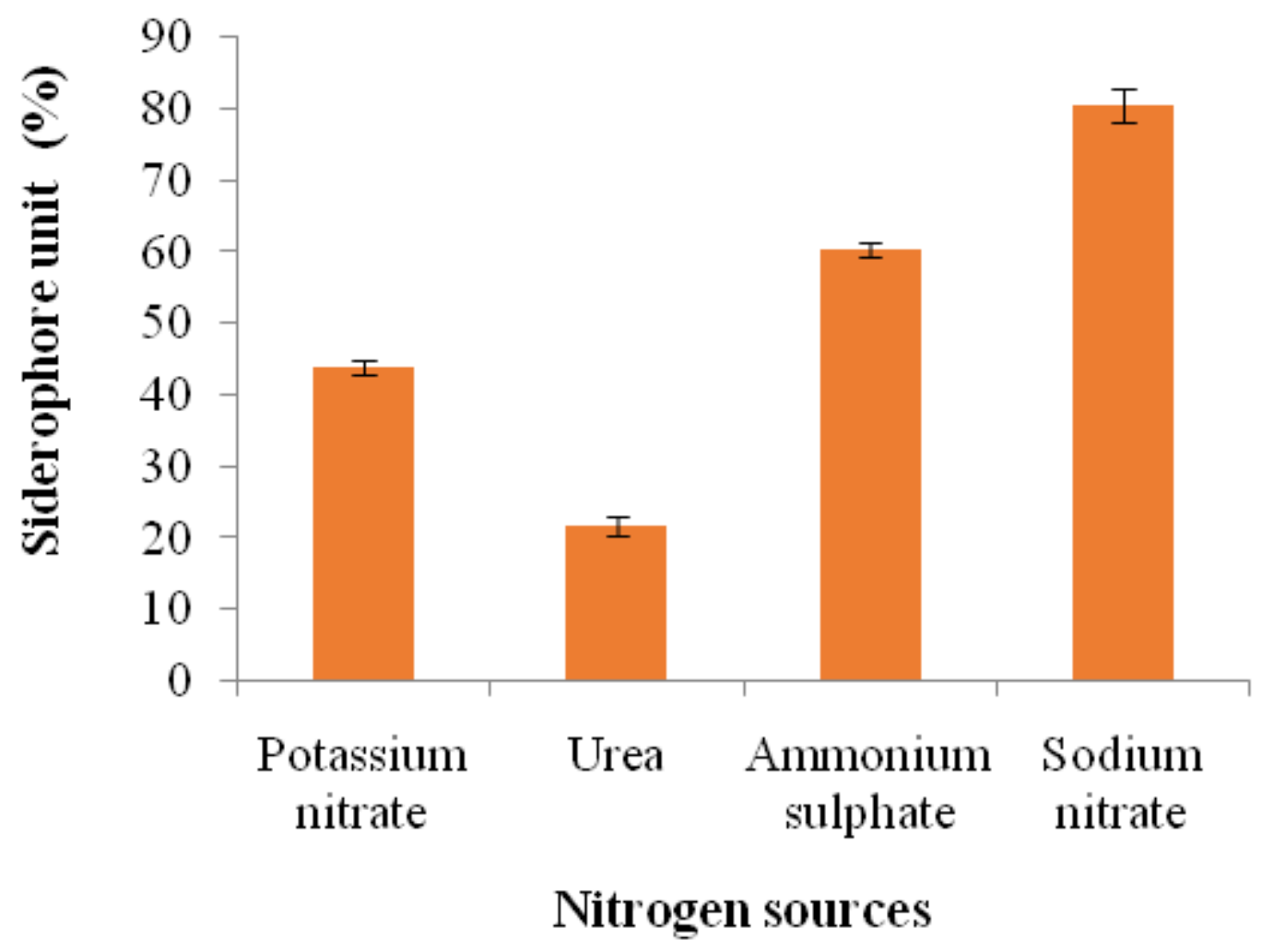

Figure 11

Effect of nitrogen sources on siderophore production by B. subtilis DR2 


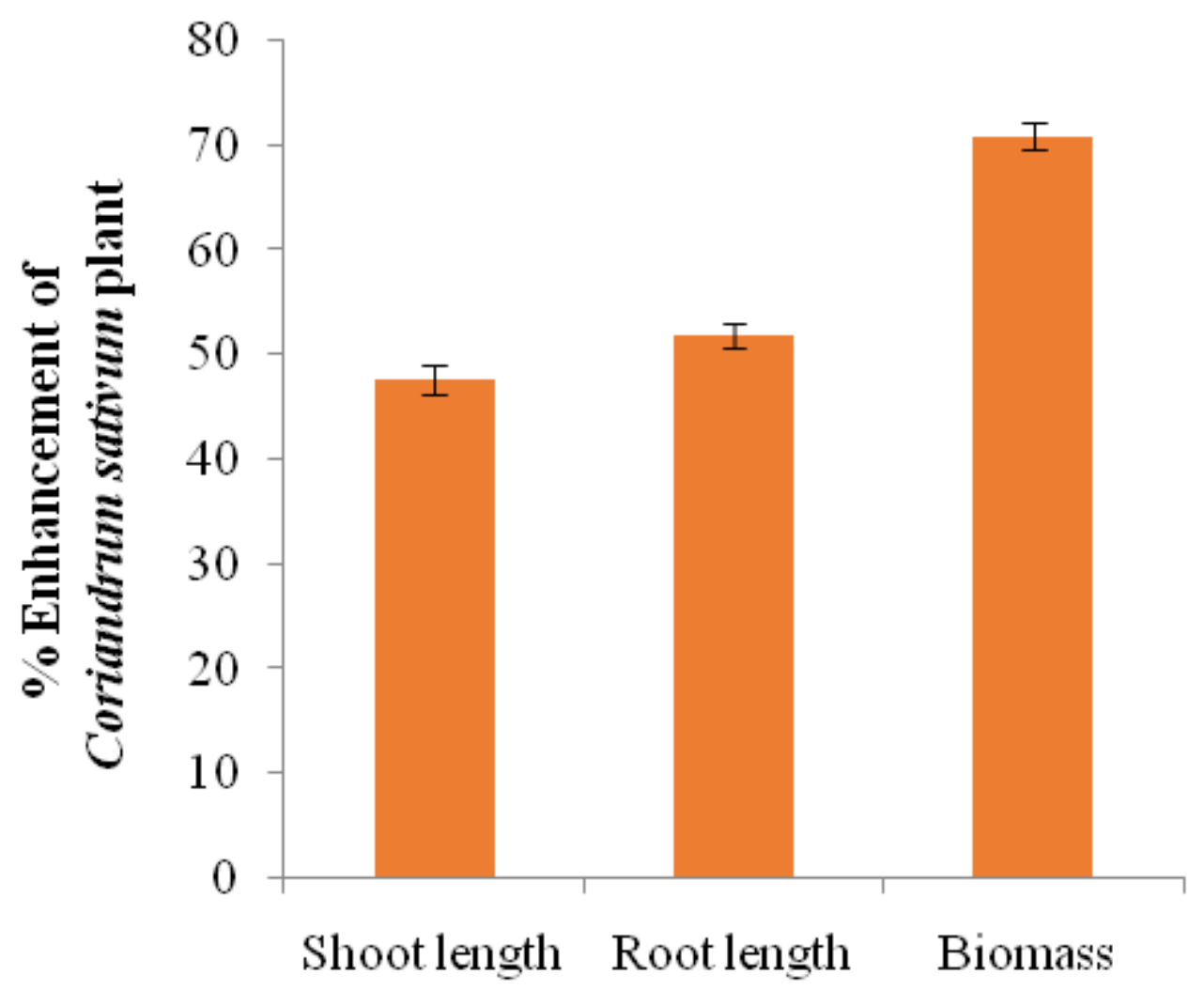

Figure 12

The \% enhancements of Coriandrum sativum plant in root length, shoot length and biomass by $\mathrm{B}$. subtilis DR2. 